\title{
Big Data: the challenge for small research groups in the era of cancer genomics
}

\author{
Aisyah Mohd Noor ${ }^{1}$, Lars Holmberg ${ }^{1,2}$, Cheryl Gillett ${ }^{1,3}$ and Anita Grigoriadis ${ }^{\star 1,4}$ \\ ${ }^{1}$ Research Oncology, Faculty of Life Sciences and Medicine, King's College London, Guy's Hospital, London SE1 9RT, UK;

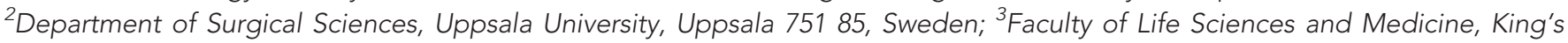 \\ Health Partners Cancer Biobank, King's College London, Research Oncology, Guy's Hospital, London SE1 9RT, UK and 'Breast \\ Cancer Now Research Unit, Research Oncology, Faculty of Life Sciences and Medicine, King's College London, Guy's Hospital, \\ London SE1 9RT, UK
}

In the past decade, cancer research has seen an increasing trend towards high-throughput techniques and translational approaches. The increasing availability of assays that utilise smaller quantities of source material and produce higher volumes of data output have resulted in the necessity for data storage solutions beyond those previously used. Multifactorial data, both large in sample size and heterogeneous in context, needs to be integrated in a standardised, cost-effective and secure manner. This requires technical solutions and administrative support not normally financially accounted for in small- to moderate-sized research groups. In this review, we highlight the Big Data challenges faced by translational research groups in the precision medicine era; an era in which the genomes of over 75000 patients will be sequenced by the National Health Service over the next 3 years to advance healthcare. In particular, we have looked at three main themes of data management in relation to cancer research, namely (1) cancer ontology management, (2) IT infrastructures that have been developed to support data management and (3) the unique ethical challenges introduced by utilising Big Data in research.

In the past decade there has been an unprecedented volume of data generation in cancer research. The emphasis on translational approaches in research, brought on by the need for accelerated, cost-effective research solutions has spurred a host of initiatives towards integration of multi-disciplinary clinical and research data to better inform research questions, including the Center for Advancing Translational Science under the National Institutes of Health (NIH, 2011) and the Cancer Research UK's Stratified Medicine Programme (Cancer Research UK, 2013). Furthermore, the development of high-throughput methods for genome interrogation, such as microarrays and next-generation sequencing (NGS), have allowed more in-depth study of tumour biology at the genetic and genomic level, leading to better targeted and personalised healthcare solutions for cancer patients. Taking breast cancer as an example, the 'Big Data' revolution has given rise to a multitude of genome-driven molecular signatures with the potential to further personalise diagnosis and treatment (Dawson et al, 2013). An increasing number of signatures are being validated and adopted into standard practice such as the
Oncotype DX (Paik et al, 2006) and Mammaprint (van't Veer et al, 2002) gene expression scores.

Although these developments have been crucial to improved cancer healthcare, they have presented a quandary to those at the heart of the growth of Big Data. Biological and clinical researchers now face increasingly large and complex data sets. Although a standard genomic microarray may profile a genome for hundreds to thousands of features per sample, current next-generation sequencers can produce over $100 \mathrm{~GB}$ of raw sequence reads per genome. These data, coupled with a plethora of clinical and phenotypic attributes, have the potential to significantly expand our understanding of disease. However, they also present nontrivial issues in data storage and analysis, issues which are relatively new in biomedicine compared with fields such as commerce and finance, where industrial-scale analyses of Big Data have been established for many years.

The relative lag in adopting Big Data in biomedicine can be attributed to three main factors: First, much of healthcare still relies on paper records and manual recording of data, despite increasing

*Correspondence: Dr A Grigoriadis; E-mail: anita.grigoriadis@kcl.ac.uk.

Received 2 April 2015; revised 4 August 2015; accepted 9 August 2015; published online 22 October 2015

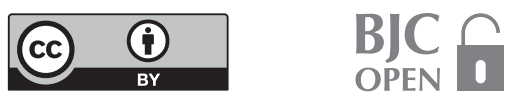


digitisation of health records, thereby leading to non-standardised, error-prone data recording (MacRury et al, 2014). Second, clinical and research data often exist in islands, separated by legal and intellectual property requirements, as well as security and confidentiality restraints (GA4GH, 2013). Third, the IT infrastructures available to researchers are ill-equipped to handle the integration and capture of heterogeneous and large-scale data, an issue that was acknowledged in a study of 17 leading academic health centres in the US (Murphy et al, 2012). At present, the real value lies not in reporting on data from these individual silos of information, but rather in the ability to bring these data together to find meaningful associations across multiple sources (Costa, 2014).

Overcoming these barriers requires the development of efficient database management systems (DBMS) that provide a centralised data source to consolidate disparate data sets. Such an example of large-scale, collaborative genomics study is the 100000 Genomes Project, recently introduced by the Department of Health with the goal of sequencing the entire genomes of over 75000 patients by 2017 to advance medical research and integrate genomics into healthcare (Genomics England, 2014). The project will leverage on collaboration between academic and commercial researchers registered in the Genomics England Clinical Interpretation Partnership (GeCIP) programme. However, such ventures raise ethical concerns regarding the flow of data and patient samples across the healthcare-research spectrum. Research groups involved in such studies will need to re-evaluate their current data management systems to adapt to these unique set of technical and ethical challenges.

\section{DATA HETEROGENEITY: ONE SIZE DOES NOT FIT ALL}

Data standards in cancer research have evolved considerably in the past decade. Rapid developments in tumour classification and drug discovery are now overtaking the rate at which they are adopted into traditional vocabularies such as the International Classification of Diseases for Oncology (ICD; Mirnezami et al, 2012). The evolution of clinical data standards has been taxonomised by medical informaticians from as early as the 1990s, covering a broad range of semantic and syntactic transitions; examples of these are pre-coordination (from 'Carcinoma in situ of the breast' in the ICD-9 to the child concepts of 'Intraductal carcinoma in situ of unspecified breast', 'Intraductal carcinoma in situ of right breast' and 'Intraductal carcinoma in situ of left breast' in the ICD-10) and obsolescence of redundant concepts (Cimino, 1996). As databases rely on the accurate classification of data, these changes have substantial effects in the way databases are modelled and structured, and subsequently in how they are queried. Therefore, current databases have a strong need for cancer ontologies that can standardise data accurately.

The ISO/IEC 11179 standards for electronic data recording provide the basis for standard medical ontologies including the Systematised Nomenclature of Medicine Clinical Terms and the Health Level Seven International (HL7) protocol as well as cancerspecific ontologies such as the NIH Cancer Data Standards Registry and Repository (caDSR) and the National Cancer Institute (NCI) Thesaurus. To conform to these standards, a metadata model is typically constructed for the data set. This can be in the form of a hierarchical data structure such as the Unified Medical Language System (Humphreys et al, 1998) which is an NIH-based medical data structure that maps data to established ontologies like HL7 and ICD-10. Metadata can also be represented through an entity-attribute-value model, which classifies concepts into an element (e.g., patient), attribute (e.g., tumour grade) and a value domain defining the range of permissible values for the element (e.g., grade 1-3). The construction of metadata is an often laborious, costly and time-consuming step in database development and requires careful planning, evaluation of the research protocols involved in the study, consultation with end-users of the database, and in the case of multi-institutional studies, examination of the legacy data models already in place in each institution. For this reason, well-curated metadata models are characteristic of large, long term clinical studies including those developed for the Surveillance, Epidemiology and End Results Program (SEER, 2008) and the NCI's Clinical Trials Cooperative Group (Komatsoulis et al, 2008).

An alternative method which may be more suited to smaller or short-term studies, is the alignment of data sets to widely available common data element (CDE) models that have been readily mapped to the ontology of choice, for instance the LexEVS model referenced upon the Enterprise Vocabulary Services (Ethier et al, 2013), and the caGRID CDE referenced upon the caDSR metadata model (Papatheodorou et al, 2009). These models serve as a 'mediator' by allowing different data sets to retain their legacy terms, while providing a unifying data model for the purposes of the study. Many other CDE mappings to ontologies have been developed and are summarised in the NIH BioPortal, which uses pattern-matching algorithms to generate mappings across $>400$ biomedical ontologies (Salvadores et al, 2013). The advantage to small research groups in this approach is the continuous, community-driven curation of these mappings, thus assuring ISO-compliant standardisation of their data sets at a cheap cost.

Besides manual curation of metadata, a common approach is the alignment of data sets to an ontology using natural language processing methods. Examples are the Dice and Dynamic algorithms that match element attributes to CDE element-attribute pairs (Ghazvinian et al, 2009) and the Apriori algorithm for automated identification of CDEs in medical records, as trained by human use (Luo et al, 2013). These methods, although dependent on established computing facilities, aid in automating the processing of free text into standardised classes of information, thereby reducing manual abstraction and human error.

Many of the proposed solutions have been generated through open-source initiatives and have been instrumental to the development of cancer databases and ontology-based applications, especially for smaller research groups. However, previous audits of commonly used cancer ontologies like the NCI Thesaurus have shown that they are far from perfect. A number of CDE's may be misclassified when matched to other ontologies (Jiang et al, 2012), and when a CDE model is rigidly enforced, may introduce inaccurate semantic mapping (Schulz et al, 2010). On one hand, this issue emphasises the requirement for periodic quality assurance of metadata models to maintain accuracy; on the other, it has prompted the practice of using less rigid data models where the database architecture is less sophisticated, as is the case in small-scale research. Community-driven efforts to develop and maintain the ontologies have been vital in keeping them up-to-date, and in sharing best practices for applying CDE normalisation to data sets (de Coronado et al, 2009). These approaches have shown that the over-arching goal is not to enforce an all-encompassing rule for the definition of data across studies, but rather to achieve a harmonisation of the consolidated data sets for the purposes of interoperability.

\section{TECHNICAL INFRASTRUCTURE-THE BASE OF THE} ICEBERG

NGS technologies are producing data faster than most underlying IT infrastructures can support and store (Mardis, 2011). NGS data require disk storage several orders of magnitude larger than standard biomedical data. Each step of NGS analysis generates large intermediate files, often requiring 5-10 times as much storage 
during the analysis phase than is required for the raw data itself. Moreover, scientists are reluctant to discard raw data, due to the continuous development of new algorithms that depend on extraction of further information from these data. Next-generation sequencing data storage and management, especially for small research groups, continue to be a major issue, due to rapidly evolving technologies producing larger and more complex data sets.

In the past, the requirement for databases in medical research confined them to traditional models of data storage that were adequately equipped for storing heterogeneous data sets. Indeed, the relational database structure represents a mature DBMS model and at the peak of its development in the 1990s was the preferred structure for some of the earliest biological databases such as the BLAST sequences and transcription factors database (Ghosh, 1990), and for clinical trial purposes the Southwest Oncology Group trials database (Blumenstein, 1989). Commercial models of relational databases including Microsoft Access (Bulusu et al, 2013), MySQL (Mosca et al, 2010) and hybrid object-relational databases such as postgreSQL and SPARQL have been widely employed in translational cancer research settings due to their open-source availability and ease of implementation (Table 1). However, relational DBMS have inflexible schemas, are not well designed for rapid growth and are prohibitively expensive for Big Data, thus their utility for NGS derived data is questionable.

In contrast to relational DBMS, non-relational database models such as NoSQL (Not Only SQL) offer high query performance, flexibility of database schema and the capacity for file-transfer across networks, albeit requiring extensive maintenance and computing power (Manyam et al, 2012). Different types of NoSQL databases, including document-based (e.g., MonoDB), columnfamily based (e.g., Cassandra or HBase) and graph-based (e.g., Bio4J) databases, have been implemented to integrate NGS with metadata. Despite their heightened requirements, NoSQLs have shown to fare better in performance tests for scalability and extensibility, as well as query retrieval times when compared with relational data models (Wang et al, 2014) and have, therefore, been employed for many Big Data projects.

To accommodate these database models across networks, recent years have seen the rise of cloud computing through the employment of remote or third party servers to store and process data on the Internet. Cloud-based solutions offer the advantage of

Table 1. Published integrative databases for cancer research

\begin{tabular}{|c|c|c|c|c|c|}
\hline Name of DB & Institution & Diseases & $\begin{array}{l}\text { No of } \\
\text { cases }\end{array}$ & DBMS & Authors \\
\hline $\begin{array}{l}\text { Breast Cancer Surgical Outcomes Research } \\
\text { Database (BRCASO) }\end{array}$ & $\begin{array}{l}\text { Group Health Cooperative, Kaiser } \\
\text { Permanente Colorado, Marshfield } \\
\text { Clinic }\end{array}$ & Breast & 6095 & SQL Server & Aiello Bowles et al. (2012) \\
\hline Pancreatic Expression Database (PED) & ICR, QMUL & Pancreas & 7636 & $\begin{array}{l}\text { MySQL, MartView } \\
\text { (BioMart), Perl }\end{array}$ & Chelala et al. (2007) \\
\hline Breast Information Core (BIC) & $\begin{array}{l}\text { International Agency for Research } \\
\text { on Cancer }\end{array}$ & Breast & - & Sybase Server, SQL, PERL & Szabo et al. (2000) \\
\hline Pathology Analytic Imaging Standards (PAIS) & Emory University & Breast, brain & 4740 & IB DB2 Server, SQL, XML & Wang et al. (2011) \\
\hline Breast Diseases Registry System (BDRS) & Middle East Technical University & Breast & - & SQL Server, XML & Kocgil and Baykal. (2007) \\
\hline $\begin{array}{l}\text { Cooperative Prostate Cancer Tissue } \\
\text { Resource (CPCTR) }\end{array}$ & University of Pittsburgh & Prostate & $>6000$ & Oracle, PL/SQL & Patel et al. (2006) \\
\hline $\begin{array}{l}\text { Pennsylvania Cancer Alliance Bioinformatics } \\
\text { Consortium (PCABC) Biorepository }\end{array}$ & University of Pittsburgh & $\begin{array}{l}\text { Melanoma, breast, } \\
\text { prostate }\end{array}$ & $>11000$ & $\begin{array}{l}\mathrm{NCl} \text { Cancer Biomedical } \\
\text { Informatics Grid (caBIG), } \\
\text { Java }\end{array}$ & Patel et al. (2007) \\
\hline METABRIC Repository & Cambridge University & Breast & 2000 & $\begin{array}{l}\text { CancerGrid, SQIV, } \\
\text { SPARQL, XML }\end{array}$ & Papatheodorou et al. (2009) \\
\hline $\begin{array}{l}\text { Genes-to-Systems Breast Cancer (G2SBC) } \\
\text { Database }\end{array}$ & $\begin{array}{l}\text { Institute for Biomedical } \\
\text { Technologies }\end{array}$ & Breast cancer & $>2000$ & MySQL, PHP, JavaScript & Mosca et al. (2010) \\
\hline SPORE Head and Neck Neoplasm Database & University of Pittsburgh & Head and neck & 6553 & Oracle, PL/SQL, Java & Amin et al. (2009) \\
\hline GEM Registry & Cambridge University & $\mathrm{Gl}$ & - & MS Access, SQL & Bulusu et al. (2013) \\
\hline Cancer Gene Expression Database (CGED) & $\begin{array}{l}\text { Nara Institute of Science and } \\
\text { Technology }\end{array}$ & Breast, GI & $>400$ & - & Kato et al. (2005) \\
\hline OncomiR Database (OncomiRdbB) & $\begin{array}{l}\text { Council of scientific and Industrial } \\
\text { Research, India }\end{array}$ & Breast & 782 & MySQL, Perl & Khurana et al. (2014) \\
\hline $\begin{array}{l}\text { Stanford Translational Research Integrated } \\
\text { Database Environment (STRIDE) }\end{array}$ & Stanford University & Various & $1.3 \mathrm{~m}$ & Oracle, XML & Lowe et al. (2009) \\
\hline $\begin{array}{l}\text { Thoracic Oncology Program Database } \\
\text { Project }\end{array}$ & University of Chicago & Thoracic & - & MS Access & Surati et al. (2011) \\
\hline Georgetown Database of Cancer (G-DOC) & Georgetown University & Breast, Gl & $>3000$ & Oracle, Java & Madhavan et al. (2011) \\
\hline $\begin{array}{l}\text { Breast Cancer Gene Expression Miner } \\
\text { (bc-GenExMiner) }\end{array}$ & $\begin{array}{l}\text { Centre de Lutte Contre le Cancer } \\
\text { Rene Gauducheau }\end{array}$ & Breast & $>3000$ & MySQL, PHP, Java & Jezequel et al. (2012) \\
\hline $\begin{array}{l}\text { Data Warehouse for Translational Research } \\
\text { (DW4TR) }\end{array}$ & Windber Research Institute & Breast & $>5000$ & Oracle, AJAX & Hu et al. (2011) \\
\hline $\begin{array}{l}\text { Danish Centre for Translational Research in } \\
\text { Breast Cancer (DCTB) }\end{array}$ & $\begin{array}{l}\text { The Danish Centre for Translational } \\
\text { Breast Cancer Research }\end{array}$ & Breast & - & - & Celis et al. (2003) \\
\hline Cancer Genomics Hub & National Cancer Institute & Various & $>11000$ & XML, Apache Solr Web & Wilks et al. (2014) \\
\hline $\begin{array}{l}\text { Catalogue of Somatic Mutations in Cancer } \\
\text { (COSMIC) }\end{array}$ & Wellcome Trust Sanger Institute & Various & - & Oracle, Biomart & Forbes et al. (2011) \\
\hline
\end{tabular}


heightened security, rapid scalability, dynamic allocation of services, and flexible costing, and can in principle ease collaboration between dispersed located research groups by using a shared environment on a 'pay-as-you-go' basis (Zhao et al, 2013). The 1000 Genomes Project, which catalogues human sequence variation through deep sequencing of the genomes of over 1000 individuals worldwide, uses a $200 \mathrm{~TB}$ Amazon cloud-based data repository solution (Clarke et al, 2012). Commercial cloud storage solutions are also provided by Google and Microsoft, and have been used by many research institutes worldwide, namely the NIH and the European Bioinformatics Institute.

These novel storage solutions have increased the availability of cancer genomics data sets. For example, the International Cancer Genome Consortium (ICGC, 2010) and The Cancer Genome Atlas (TCGA, 2006) each store over two petabytes of genomic data across 34 cancer types. Their application to the clinic through the Mutational Signature Analysis (Alexandrov et al, 2013) and Pan-Cancer analysis (The Cancer Genome Atlas Research Network et al, 2013) studies have provided the essential link between large-scale genomics and translational research. These data sets can often be downloaded in a smaller manageable intermediate format. Services like Cancer Genomics Hub (Wilks et al, 2014), the Database of Genotypes and Phenotypes (NIH, 2007), the European Genome Archive (Lappalainen et al, 2015) and the European Nucleotide Archive (Leinonen et al, 2011), allow users to access, query and download regions of interest from raw large-scale sequencing data sets, whereas databases like the Catalogue of Somatic Mutations in Cancer (Bamford et al, 2004) and the cBioPortal for Cancer Genomics (Cerami et al, 2012) provide curated published data. Efforts to make these data publicly available, most notably a recent decision by the NIH to lift its restriction on the use of cloud computing (Stein et al, 2015), have enabled greater access to these valuable data resources by small research groups that do not have the sequencing facilities to generate these data.

Finally, cloud compute models have provided cost-effective solutions for small research groups looking to conduct sequencing analysis. These can be broadly separated into three groups, those that (1) run applications on the cloud and hide infrastructure implementation from the user; (2) provide infrastructure as a service; or (3) provide database and software as a service. One example of the latter is the Globus Genomics System (Madduri et al, 2014), which is an Amazon cloud-based analysis and data management client built on the open-source, web-based Galaxy platform (Goecks et al, 2010). The advantage of such a platform is its use of elastic scaling of compute clusters, multi-threaded parallelism of workflows and a secure file-transfer system. These features, coupled with its intuitive interface and the continuous reduction of cloud-computing costs, make it an attractive option for small research groups looking to perform short-term or modest-sized NGS projects. Alternative data management systems that allow users to integrate large-scale genomics data and various metadata are TranSMART (Athey et al, 2013), BioMart (Kasprzyk, 2011) and the Integrated Rule-Oriented Data System (iRODS, 2015). These platforms provide extensive modules for data integration, and have been employed globally for cost-effective, collaborative data storage for small-scale research settings.

ETHICS OF GENOMIC RESEARCH: PERSONALISATION VS EXPOSURE

The increased adoption of genomic research in personalised medicine, particularly with the recent 100000 Genome project, has stirred strong public debate. Genomic research poses new challenges for tissue banks and research ethics committees that may not necessarily be addressed by existing guidelines, such as the use of a tumour sample from one patient for multiple studies (due to assays now requiring smaller quantities of tissue) and the appropriate protocol for feedback of results to patients. Furthermore, studies have demonstrated the 're-identifiability' of apparently anonymised samples of single nucleotide polymorphism data from genome-wide association studies (GWAS). This has been achieved by searching Y-chromosome genotypes and matched demographic information in recreational genetic genealogy databases (Gymrek et al, 2013) or the extrapolation of individual patient disease states by matching a patient's genotype to the cohort's aggregate association results, both of which are commonly published in GWAS studies (Lumley and Rice, 2010). Coupled with the growing use of cloud-based storage systems that have eased accessibility of data on the Internet, these have led to ethical concerns surrounding the nature of participant consent in genomic research and the adequacy of current systems in protecting privacy and security.

In the UK, the NHS Health Research Authority applies legislative checkpoints governing the use of patient data or specimens, which have been adhered to through various methods. For example, biobanks use a 'broad consent' format to address the complexity of genomic studies and to enable research use over a long time period (Hansson, 2009). The capture of tiered or selective consent has been attempted through coding systems to maximise use of data between research groups and to provide assurance that the appropriate consent has been given for their study (Ohno-Machado et al, 2012). Alternatively, the 'honest broker' model has been used, in which an impartial third party performs the collection, de-identification and provision of patient data to researchers. Health information is stripped of identifiable items within the honest broker environment and assigned a research identifier, which then allows updating of clinical information as well as feedback of results to patients wherever necessary. Through the honest broker system, researchers are granted more independence and consistency in data sharing, however this comes at a logistical cost to the biobank and limits the speed at which data requests can be managed.

In the case of research databases, several methods have been used to conform to regulatory frameworks. One example is the development of de-identification algorithms that scan free-text reports and remove or encrypt identifiable information (Schell, 2006; Fernandes et al, 2013). These algorithms have been widely reviewed (Dhir et al, 2008). Another example is the linkage of a research database to the honest broker environment through their research identifiers, thus reducing the delays associated with updated data requests (Segagni et al, 2012). For multi-institutional databases, system-generated identifiers have been proposed to allow for institutions to use their own consent language and ethics procedures (Patel et al, 2007). Finally, customised user interfaces have been developed to allow users to view descriptive statistics of aggregate data according to level of authorisation - one such application is used by the Pennsylvania Cancer Alliance Bioinformatics Consortium, with views divided into 'public query', 'approved investigator query' and 'data manager query' (Patel et al, 2006).

On-going discussions between healthcare providers, patients and government have indicated that a consensus has yet to be reached regarding best practices in governance of patient data (POST Report 474, 2014). It is however agreed that the use of the national healthcare data resource requires transparency and constant engagement with the public, as illustrated by the Department of Health's consultation for proposing new regulations of data use (Department of Health, 2014). Although this continues to be debated, research groups should operate on robust regulatory procedures that protect patient privacy, while not being overlaid with obstructive administrative barriers that may be prohibitive to research (Karp et al, 2008). 
AN INTEGRATIVE RESEARCH DATABASE SOLUTION FOR SMALL-TO-MODERATE-SIZED RESEARCH GROUPS

The Department of Research Oncology (RO) at King's College London, UK is a typical example of a moderate-sized research group working at the translational interface in breast cancer research. Over the years, a rich resource of research data has been generated from a multitude of sources, including medical records, histopathology, genomics, imaging and so on (Figure 1), as a result of its extensive involvement in experimental studies across a wide variety of platforms such as in vitro, in vivo and in silico (microarray and NGS) models, as well as cancer clinical trials.

Given the RO's physical location within an NHS healthcare centre, our research has also leveraged on the integration of associated patient and sample data from collaborations with the King's Health Partners Cancer Biobank (KHP-CB) and Clinical Genetics Department at Guy's Hospital. In light of a growing number of integrative projects across the department, notably the RO's forthcoming participation in the GeCIP programme, a researcher-driven database was created to facilitate the interoperability of our research. We employed a previously described CDE model (Papatheodorou et al, 2009) based on ISO-compliant data formats recommended by the caDSR. To conform to the data model, data normalisation was carried out on over 2000 records spanning over 200 attributes including clinical, pathological, genomic, transcriptomic, mouse model and imaging data. Normalisation involved standardisation of data formats and semantic transformation of attributes, after consultation with clinical specialists. The description of each CDE is stored in a data dictionary, which forms the 'minimum required set' of any new data to be entered in the database. To comply with security standards, access tier was recorded to reflect the level of consent given by the patient for data use, with consent procedures set by the KHP-CB through an honest broker system. The database uses an open-source relational MySQL platform and front-end utilities for ease of querying. For larger high-throughput data from microarray and sequencing platforms, the files are stored as links in the database for querying and association with clinical data, which point to directories in our storage servers.

Taking the necessary precautions in mapping these diverse data sets to the data model and ensuring compliance with ethical standards, we believe our database presents a cost-effective, interoperable solution for the transformation of complex, heterogeneous data into actionable information for translational research from which to build a solid foundation for participating in the GeCIP endeavour.

\section{HARNESSING BIG DATA IN SMALL-SCALE RESEARCH}

The move towards high-throughput translational research in cancer has led to an explosion of genomic Big Data. However, the adoption of robust yet accessible storage systems and informatics workflows in parallel with this data growth, particularly among small-to-moderate-sized research groups, has not been well documented. In this review, we have highlighted the main issues introduced by Big Data and provide a summary of potential solutions adopted by researchers to address them.

The problem of data heterogeneity has largely been dealt with by using in-house models of standardisation to fit the distinct requirements of individual research groups. These have been aided by the publication of comprehensive guides for adaptation of legacy data with modern concepts, ranging from common classes of evolution in medical vocabularies to guide data transformation (Cimino, 1998) and ways to address conceptual gaps and redundancies in data models (Richesson and Krischer, 2007). In recognition of the labour and financial costs associated with data storage, small research groups have moved toward open-source, community-driven initiatives for data management. The utility of these solutions for researchers in the Genomics England era cannot be understated, and will be instrumental for harnessing genomic Big Data in small research groups.

On-going debate about ethical use of genomic data emphasises the need for transparency in communicating genomic research to patients. Recent concerns raised by the public in response to the NHS 'care.data' scheme exemplify the need to regain public trust on the collection and security of data for healthcare (Nature, 2014). Although previous studies have illustrated the difficulty in extracting privacy risk in genomic data, the last decade has seen renewed efforts to quantify the likelihood of an individual being identified through their genomic data using simulation tests to assess re-identifiability of data sets. This has led to the development of algorithms to prevent re-identification (Benitez and Malin, 2010) as well as stricter guidelines on the publication of GWAS data to reduce re-identification without compromising the reproducibility of the studies (Lumley and Rice, 2010). Biobanks will

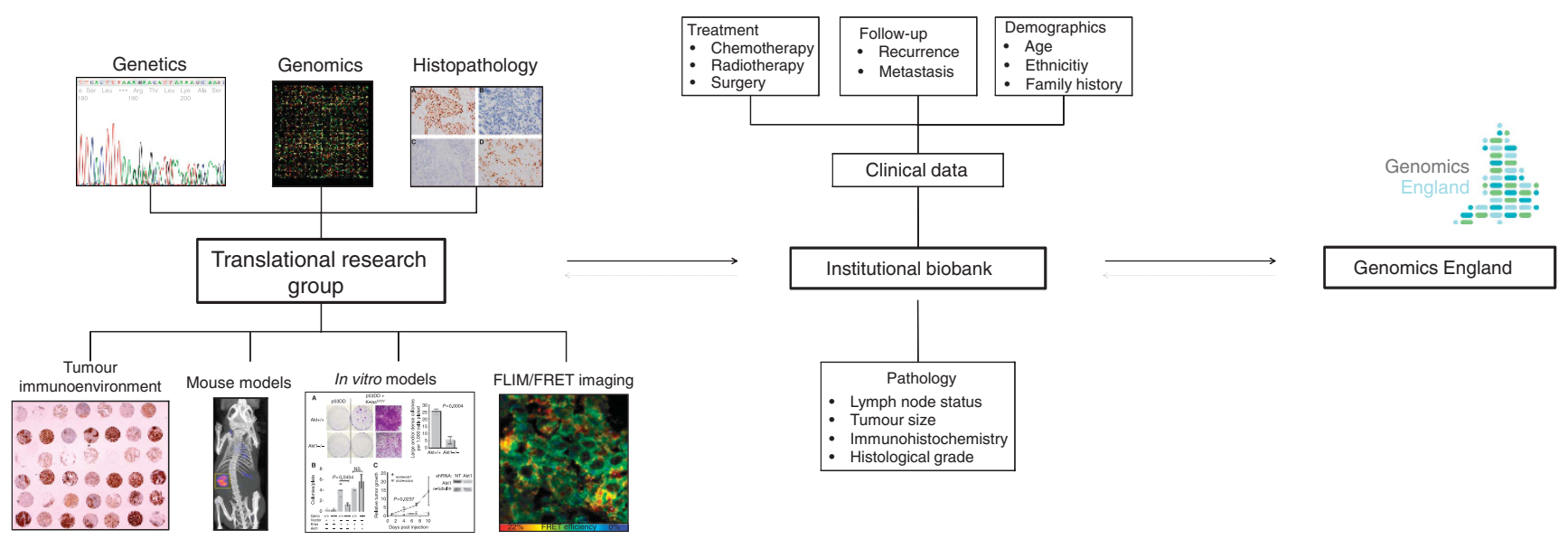

Figure 1. Translational research data in the era of Genomics England. Research data from multi-disciplinary fields such as genomics, histopathology, mouse models and fluorescence imaging as managed by a typical translational research group will be integrated with their associated clinical data managed by the institutional biobank and healthcare centre, encompassing features such as treatment, follow-up, demographic and diagnostic data. In alliance with the Genomics England project, these data and their associated biosamples will be used in $\mathrm{GeCIP}$ studies and fed back to both healthcare and on-going translational studies within the research group. 
need to adapt to the evolution of genomic Big Data by supporting a consent infrastructure that can proactively audit donor-sharing policies and continuously track privacy risks incurred for individuals while maximising the sharing of information.

Finally, the rise of genomic data availability prompts the reminder that genomic studies and biomarkers, however advanced they may be, should be subject to the same rigorous standards and inference as any other scientific investigation. Studies of the impact of an individual characteristic or exposure, such as ethnicity, histopathological tumour type or chemotherapy on an outcome require a careful definition of the population studied, comparison groups, measurements, interventions and all other elements of a scientific clinical study, and no amount of precision or detail can correct for bias and confounding factors (Prudkin and Nuciforo, 2015). The lack of a firm strategy and well-planned study design has hindered the translation of biomarkers to clinical utility, and a growing number of publications and institutional initiatives aim to improve this issue (Staratschek-Jox and Schultze, 2010; Poste et al, 2015). One effective infrastructure to support a shorter way between first discovery and clinical application is a truly multi-disciplinary and multi-professional collaboration from the planning stage through to analysis and interpretation (Poste et al, 2015).

The decreasing cost of sequencing has improved the financial feasibility of large-scale studies such as the 100000 Genomes Project, yet it is estimated that the cost of storing these data is not decreasing in parallel (Stein, 2010). The onus will be on individual research groups to equip themselves with the appropriate infrastructure necessary to accommodate these data. The success of these projects will in turn depend on the establishment of frameworks that incorporate accurate cancer ontology, proper study design, appropriate ethical standards and robust IT infrastructure. Overall, the challenges brought on by Big Data will enforce stronger interaction within the scientific community in using these resources effectively for translational cancer research.

\section{ACKNOWLEDGEMENTS}

The authors thank Prof. Andrew Tutt for allowing us to work on the Breakthrough Breast Cancer Research Unit cohort, and Hyder Tahir and Dr Anca Mera for their support with clinical data interpretation. Drs Patrycja Gazinska and Gilbert Frühwirth provided images for Figure 1. We would like to thank Dr Caroline Johnston and Mamunur Rashid for critically reading the manuscript. KHP-CB is supported by the Department of Health via the National Institute for Health Research (NIHR) comprehensive Biomedical Research Centre award and the Experimental Cancer Centre at King's College London. AG is supported by Breakthrough Breast Cancer Research UK. AMN is the recipient of a postgraduate award under Majlis Amanah Rakyat Malaysia.

\section{CONFLICT OF INTEREST}

The authors declare no conflict of interest.

\section{REFERENCES}

Aiello Bowles EJ, Feigelson HS, Barney T, Broecker K, Sterrett A, Bischoff K, Engel J, Gundersen G, Sheehey-Jones J, Single R, Onitilo A, James TA, McCahill LE (2012) Improving quality of breast cancer surgery through development of a national breast cancer surgical outcomes (BRCASO) research database. BMC Cancer 12: 136.

Alexandrov LB, Nik-Zainal S, Wedge DC, Aparicio SA, Behjati S, Biankin AV, Bignell GR, Bolli N, Borg A, Borresen-Dale AL, Boyault S, Burkhardt B,
Butler AP, Caldas C, Davies HR, Desmedt C, Eils R, Eyfjord JE, Foekens JA, Greaves M, Hosoda F, Hutter B, Ilicic T, Imbeaud S, Imielinski M, Jager N, Jones DT, Jones D, Knappskog S, Kool M, Lakhani SR, Lopez-Otin C, Martin S, Munshi NC, Nakamura H, Northcott PA, Pajic M, Papaemmanuil E, Paradiso A, Pearson JV, Puente XS, Raine K, Ramakrishna M, Richardson AL, Richter J, Rosenstiel P, Schlesner M, Schumacher TN, Span PN, Teague JW, Totoki Y, Tutt AN, Valdes-Mas R, van Buuren MM, van 't Veer L, Vincent-Salomon A, Waddell N, Yates LR, Zucman-Rossi J, Futreal PA, McDermott U, Lichter P, Meyerson M, Grimmond SM, Siebert R, Campo E, Shibata T, Pfister SM, Campbell PJ, Stratton MR (2013) Signatures of mutational processes in human cancer. Nature 500(7463): 415-421.

Amin W, Kang HP, Egloff AM, Singh H, Trent K, Ridge-Hetrick J, Seethala RR, Grandis J, Parwani AV (2009) An informatics supported web-based data annotation and query tool to expedite translational research for head and neck malignancies. BMC Cancer 9: 396.

Athey BD, Braxenthaler M, Haas M, Guo Y (eds) (2013) tranSMART: an open source and community-driven informatics and data sharing platform for clinical and translational research. Proceedings of the Conference on AMIA Joint Summits on Translational Science proceedings AMIA Summit on Translational Science 2013: 6-8.

Bamford S, Dawson E, Forbes S, Clements J, Pettett R, Dogan A, Flanagan A, Teague J, Futreal PA, Stratton MR, Wooster R (2004) The COSMIC (Catalogue of Somatic Mutations in Cancer) database and website. Br J Cancer 91(2): 355-358.

Benitez K, Malin B (2010) Evaluating re-identification risks with respect to the HIPAA privacy rule. J Am Med Inform Assoc 17(2): 169-177.

Blumenstein BA (1989) The relational database model and multiple multicenter clinical trials. Control Clin Trials 10(4): 386-406.

Bulusu VR, Fullarton J, Leahy M, Morgan C, Rasheed A, Taniere P, Toh S, Verrill M, White J, Judson I (2013) Rationale and design of a UK database for a rare cancer type: the GEM Registry for gastrointestinal stromal tumours. Br J Cancer 109(6): 1403-1407.

Cancer Research UK (2013) Stratified Medicine Programme: Cancer Research UK. Chelala C, Hahn SA, Whiteman HJ, Barry S, Hariharan D, Radon TP, Lemoine NR, Crnogorac-Jurcevic T (2007) Pancreatic Expression database: a generic model for the organization, integration and mining of complex cancer datasets. BMC genomics 8: 439.

Celis JE, Gromov P, Gromova I, Moreira JM, Cabezon T, Ambartsumian N, Grigorian M, Lukanidin E, Thor Straten P, Guldberg P, Bartkova J, Bartek J, Lukas J, Lukas C, Lykkesfeldt A, Jaattela M, Roepstorff P, Bolund L, Orntoft T, Brunner N, Overgaard J, Sandelin K, Blichert-Toft M, Mouridsen H, Rank FE (2003) Integrating proteomic and functional genomic technologies in discovery-driven translational breast cancer research. Mol Cell Proteomics 2(6): 369-377.

Cerami E, Gao J, Dogrusoz U, Gross BE, Sumer SO, Aksoy BA, Jacobsen A, Byrne CJ, Heuer ML, Larsson E, Antipin Y, Reva B, Goldberg AP, Sander C, Schultz N (2012) The cBio cancer genomics portal: an open platform for exploring multidimensional cancer genomics data. Cancer Discov 2(5): 401-404.

Cimino JJ (1996) Formal descriptions and adaptive mechanisms for changes in controlled medical vocabularies. Methods Inf Med 35(3): 202-210.

Cimino JJ (1998) Desiderata for controlled medical vocabularies in the twenty-first century. Methods Inf Med 37(4-5): 394-403.

Clarke L, Zheng-Bradley X, Smith R, Kulesha E, Xiao C, Toneva I, Vaughan B, Preuss D, Leinonen R, Shumway M, Sherry S, Flicek P (2012) The 1000 genomes project: data management and community access. Nat Methods 9(5): 459-462.

Costa FF (2014) Big data in biomedicine. Drug Discov Today 19(4): 433-440. Dawson SJ, Rueda OM, Aparicio S, Caldas C (2013) A new genome-driven integrated classification of breast cancer and its implications. EMBO J 32(5): 617-628.

de Coronado S, Wright LW, Fragoso G, Haber MW, Hahn-Dantona EA, Hartel FW, Quan SL, Safran T, Thomas N, Whiteman L (2009) The NCI Thesaurus quality assurance life cycle. J Biomed Inform 42(3): 530-539.

Department of Health (2014) Protecting health and care information: a consultation on proposals to introduce new regulations.

Dhir R, Patel AA, Winters S, Bisceglia M, Swanson D, Aamodt R, Becich MJ (2008) A multidisciplinary approach to honest broker services for tissue banks and clinical data: a pragmatic and practical model. Cancer 113(7): 1705-1715. 
Ethier JF, Dameron O, Curcin V, McGilchrist MM, Verheij RA, Arvanitis TN, Taweel A, Delaney BC, Burgun A (2013) A unified structural/ terminological interoperability framework based on LexEVS: application to TRANSFoRm. J Am Med Inform Assoc 20(5): 986-994.

Fernandes AC, Cloete D, Broadbent MT, Hayes RD, Chang CK, Jackson RG, Roberts A, Tsang J, Soncul M, Liebscher J, Stewart R, Callard F (2013) Development and evaluation of a de-identification procedure for a case register sourced from mental health electronic records. BMC Med Inform Decis Mak 13: 71 .

Forbes SA, Bindal N, Bamford S, Cole C, Kok CY, Beare D, Jia M, Shepherd R, Leung K, Menzies A, Teague JW, Campbell PJ, Stratton MR, Futreal PA (2011) COSMIC: mining complete cancer genomes in the Catalogue of Somatic Mutations in Cancer. Nucleic Acids Res 39(Database issue): D945-D950.

GA4GH (2013) Creating a Global Alliance to Enable Responsible Sharing of Genomic and Clinical Data.

Genomics (2014) The 100000 Genomes Project. Available from http://www.genomicsengland.co.uk/ (accessed 1 February 2015).

Ghazvinian A, Noy NF, Musen MA (2009) Creating mappings for ontologies in biomedicine: simple methods work. AMIA Annu Symp Proc 2009: 198-202.

Ghosh D (1990) A relational database of transcription factors. Nucleic Acids Res 18(7): 1749-1756.

Goecks J, Nekrutenko A, Taylor J (2010) Galaxy: a comprehensive approach for supporting accessible, reproducible, and transparent computational research in the life sciences. Genome Biol 11(8): R86.

Gymrek M, McGuire AL, Golan D, Halperin E, Erlich Y (2013) Identifying personal genomes by surname inference. Science 339(6117): 321-324.

Hansson MG (2009) Ethics and biobanks. Br J Cancer 100(1): 8-12.

Hu H, Correll M, Kvecher L, Osmond M, Clark J, Bekhash A, Schwab G, Gao D, Gao J, Kubatin V, Shriver CD, Hooke JA, Maxwell LG, Kovatich AJ, Sheldon JG, Liebman MN, Mural RJ (2011) DW4TR: A Data Warehouse for Translational Research. J Biomed Inform 44(6): 1004-1019.

Humphreys BL, Lindberg DAB, Schoolman HM, Barnett GO (1998) The Unified Medical Language System: an informatics research collaboration. J Am Med Inform Assoc 5(1): 1-11.

ICGC (2010) International network of cancer genome projects. Nature 464(7291): 993-998.

iRODS (2015) The Integrated Rule-Oriented Data System (iRODS). Available from http://irods.org/ (accessed 30 July 2015).

Jezequel P, Campone M, Gouraud W, Guerin-Charbonnel C, Leux C, Ricolleau G, Campion L (2012) bc-GenExMiner: an easy-to-use online platform for gene prognostic analyses in breast cancer. Breast Cancer Res Treat 131(3): 765-775.

Jiang G, Solbrig HR, Chute CG (2012) Quality evaluation of value sets from cancer study common data elements using the UMLS semantic groups. J Am Med Inform Assoc 19(e1): e129-e136.

Karp DR, Carlin S, Cook-Deegan R, Ford DE, Geller G, Glass DN, Greely H, Guthridge J, Kahn J, Kaslow R, Kraft C, MacQueen K, Malin B, Scheuerman RH, Sugarman J (2008) Ethical and practical issues associated with aggregating databases. PLoS Med 5(9): e190.

Kasprzyk A (2011) BioMart: driving a paradigm change in biological data management. Database (Oxford) 2011: bar049.

Kato K, Yamashita R, Matoba R, Monden M, Noguchi S, Takagi T, Nakai K (2005) Cancer gene expression database (CGED): a database for gene expression profiling with accompanying clinical information of human cancer tissues. Nucleic Acids Res 33(Database issue): D533-D536.

Khurana R, Verma VK, Rawoof A, Tiwari S, Nair RA, Mahidhara G, Idris MM, Clarke AR, Kumar LD (2014) OncomiRdbB: a comprehensive database of microRNAs and their targets in breast cancer. BMC Bioinformatics 15: 15 .

Kocgil OD, Baykal N (2007) An integrated approach to breast diseases and breast cancer registry and research: BDRS as a web-based multiinstitutional model. Comput Biol Med 37(10): 1414-1425.

Komatsoulis GA, Warzel DB, Hartel FW, Shanbhag K, Chilukuri R, Fragoso G, Coronado S, Reeves DM, Hadfield JB, Ludet C, Covitz PA (2008) caCORE version 3: implementation of a model driven, serviceoriented architecture for semantic interoperability. J Biomed Inform 41(1): 106-123.

Lappalainen I, Almeida-King J, Kumanduri V, Senf A, Spalding JD, ur-Rehman S, Saunders G, Kandasamy J, Caccamo M, Leinonen R, Vaughan B, Laurent T, Rowland F, Marin-Garcia P, Barker J, Jokinen P, Torres AC, de Argila JR, Llobet OM, Medina I, Puy MS, Alberich M, de la Torre S, Navarro A, Paschall J, Flicek P (2015) The European Genome-phenome Archive of human data consented for biomedical research. Nat Genet 47(7): 692-695.

Leinonen R, Akhtar R, Birney E, Bower L, Cerdeno-Tarraga A, Cheng Y, Cleland I, Faruque N, Goodgame N, Gibson R, Hoad G, Jang M, Pakseresht N, Plaister S, Radhakrishnan R, Reddy K, Sobhany S, Ten Hoopen P, Vaughan R, Zalunin V, Cochrane G (2011) The European Nucleotide Archive. Nucleic Acids Res 39: D28-D31 (Database issue).

Lowe HJ, Ferris TA, Hernandez PM, Weber SC (2009) STRIDE-An integrated standards-based translational research informatics platform. AMIA Annu Symp Proc 2009: 391-395.

Lumley T, Rice K (2010) Potential for revealing individual-level information in genome-wide association studies. JAMA 303(7): 659-660.

Luo Z, Miotto R, Weng C (2013) A human-computer collaborative approach to identifying common data elements in clinical trial eligibility criteria. J Biomed Inform 46(1): 33-39.

MacRury S, Finlayson J, Hussey-Wilson S, Holden S (2014) Development of a pseudo/anonymised primary care research database: proof-of-concept study. Health Informatics J; e-pub ahead of print 15 June 2014.

Madduri RK, Sulakhe D, Lacinski L, Liu B, Rodriguez A, Chard K, Dave UJ, Foster IT (2014) Experiences building Globus Genomics: a nextgeneration sequencing analysis service using Galaxy, Globus, and Amazon Web Services. Concurr Comput 26(13): 2266-2279.

Madhavan S, Gusev Y, Harris M, Tanenbaum DM, Gauba R, Bhuvaneshwar K, Shinohara A, Rosso K, Carabet LA, Song L, Riggins RB, Dakshanamurthy S, Wang Y, Byers SW, Clarke R, Weiner LM (2011) G-DOC: A Systems Medicine Platform for Personalized Oncology. Neoplasia 13(9): 771-783.

Manyam G, Payton MA, Roth JA, Abruzzo LV, Coombes KR (2012) Relax with CouchDB-into the non-relational DBMS era of bioinformatics. Genomics 100(1): 1-7.

Mardis ER (2011) A decade's perspective on DNA sequencing technology. Nature 470(7333): 198-203.

Mirnezami R, Nicholson J, Darzi A (2012) Preparing for precision medicine. $N$ Engl J Med 366(6): 489-491.

Mosca E, Alfieri R, Merelli I, Viti F, Calabria A, Milanesi L (2010) A multilevel data integration resource for breast cancer study. BMC Syst Biol 4: 76.

Murphy SN, Dubey A, Embi PJ, Harris PA, Richter BG, Turisco F, Weber GM, Tcheng JE, Keogh D (2012) Current state of information technologies for the clinical research enterprise across academic medical centers. Clin Transl Sci 5(3): 281-284.

Nature (2014) Careless.data. Nature 507(7490): 7. Available at http://www.nature.com/news/careless-data-1.14802.

NIH (2007) The database of Genotypes and Phenotypes (dbGaP).

NIH (2011) National Institutes of Health: National Center for Advancing Translational Sciences (NCATS). Available from http:// www.ncats.nih.gov/ (accessed 30 July 2015).

Ohno-Machado L, Bafna V, Boxwala AA, Chapman BE, Chapman WW, Chaudhuri K, Day ME, Farcas C, Heintzman ND, Jiang X, Kim H, Kim J, Matheny ME, Resnic FS, Vinterbo SA. the iDASH team (2012) iDASH: integrating data for analysis, anonymization, and sharing. J Am Med Inform Assoc 19(2): 196-201.

Paik S, Tang G, Shak S, Kim C, Baker J, Kim W, Cronin M, Baehner FL, Watson D, Bryant J, Costantino JP, Geyer Jr CE, Wickerham DL, Wolmark N (2006) Gene expression and benefit of chemotherapy in women with node-negative, estrogen receptor-positive breast cancer. J Clin Oncol 24(23): 3726-3734.

Papatheodorou I, Crichton C, Morris L, Maccallum P, Davies J, Brenton JD, Caldas C (2009) A metadata approach for clinical data management in translational genomics studies in breast cancer. BMC Med Genomics 2: 66-66.

Patel AA, Gilbertson JR, Parwani AV, Dhir R, Datta MW, Gupta R, Berman JJ, Melamed J, Kajdacsy-Balla A, Orenstein J, Becich MJ. Cooperative Prostate Cancer Tissue R (2006) An informatics model for tissue banks-lessons learned from the Cooperative Prostate Cancer Tissue Resource. BMC Cancer 6: 120.

Patel AA, Gilbertson JR, Showe LC, London JW, Ross E, Ochs MF, Carver J, Lazarus A, Parwani AV, Dhir R, Beck JR, Liebman M, Garcia FU, Prichard J, Wilkerson M, Herberman RB, Becich MJ. PCABC (2007) A novel cross-disciplinary multi-institute approach to translational cancer research: lessons learned from Pennsylvania Cancer Alliance Bioinformatics Consortium (PCABC). Cancer Inform 3: 255-274. 
POST Report 474 (2014) Big Data and Public Health. Parliamentary Office of Science and Technology (POST)(PN474).

Poste G, Compton CC, Barker AD (2015) The national biomarker development alliance: confronting the poor productivity of biomarker research and development. Expert Rev Mol Diagn 15(2): 211-218.

Prudkin L, Nuciforo P (2015) Obstacles to precision oncology: confronting current factors affecting the successful introduction of biomarkers to the clinic. Cell Oncol 38(1): 39-48.

Richesson RL, Krischer J (2007) Data standards in clinical research: gaps, overlaps, challenges and future directions. J Am Med Inform Assoc 14(6): 687-696.

Salvadores M, Alexander PR, Musen MA, Noy NF (2013) BioPortal as a dataset of linked biomedical ontologies and terminologies in RDF. Semant Web 4(3): 277-284.

Schell SR (2006) Creation of clinical research databases in the 21st century: a practical algorithm for HIPAA Compliance. Surg Infect (Larchmt) 7(1): $37-44$.

Schulz S, Schober D, Tudose I, Stenzhorn H (2010) The Pitfalls of thesaurus ontologization-the case of the NCI thesaurus. AMIA Annu Symp Proc 2010: 727-731.

SEER (2008) SEER Breast Cancer Database, 2007 Creation and Characterization. Available from http://www.lifemath.net/cancer/about/ techreports/technical_report_7b.pdf (accessed 30 July 2015).

Segagni D, Tibollo V, Dagliati A, Zambelli A, Priori SG, Bellazzi R (2012) An ICT infrastructure to integrate clinical and molecular data in oncology research. BMC Bioinformatics 13(Suppl 4): S5.

Staratschek-Jox A, Schultze JL (2010) Re-overcoming barriers in translating biomarkers to clinical practice. Expert Opin Med Diagn 4(2): 103-112.

Stein L (2010) The case for cloud computing in genome informatics. Genome Biol 11(5): 207.

Stein LD, Knoppers BM, Campbell P, Getz G, Korbel JO (2015) Data analysis: create a cloud commons. Nature 523(7559): 149-151.

Surati M, Robinson M, Nandi S, Faoro L, Demchuk C, Kanteti R, Ferguson B, Gangadhar T, Hensing T, Hasina R, Husain A, Ferguson M, Karrison T, Salgia R (2011) Generation of comprehensive thoracic oncology database-tool for translational research. J Vis Exp; e-pub ahead of print 22 January 2011; doi:10.3791/2414.
Szabo C, Masiello A, Ryan JF, Brody LC (2000) The breast cancer information core: database design, structure, and scope. Hum Mutat 16(2): 123-131.

TCGA (2006) The Cancer Genome Atlas. Available from http:// cancergenome.nih.gov/ (accessed 30 July 2015).

The Cancer Genome Atlas Research NetworkWeinstein JN, Collisson EA, Mills GB, Shaw KRM, Ozenberger BA, Ellrott K, Shmulevich I, Sander C, Stuart JM (2013) The Cancer Genome Atlas Pan-Cancer analysis project. Nat Genet 45(10): 1113-1120.

van't Veer LJ, Dai H, van de Vijver MJ, He YD, Hart AA, Mao M, Peterse HL, van der Kooy K, Marton MJ, Witteveen AT, Schreiber GJ, Kerkhoven RM, Roberts C, Linsley PS, Bernards R, Friend SH (2002) Gene expression profiling predicts clinical outcome of breast cancer. Nature 415(6871): $530-536$.

Wang F, Kong J, Cooper L, Pan T, Kurc T, Chen W, Sharma A, Niedermayr C, Oh TW, Brat D, Farris AB, Foran DJ, Saltz J (2011) A data model and database for high-resolution pathology analytical image informatics. J Pathol Inform 2: 32.

Wang S, Pandis I, Wu C, He S, Johnson D, Emam I, Guitton F, Guo Y (2014) High dimensional biological data retrieval optimization with NoSQL technology. BMC genomics 15(Suppl 8): S3-S3.

Wilks C, Cline MS, Weiler E, Diehkans M, Craft B, Martin C, Murphy D, Pierce H, Black J, Nelson D, Litzinger B, Hatton T, Maltbie L, Ainsworth M, Allen P, Rosewood L, Mitchell E, Smith B, Warner J, Groboske J, Telc H, Wilson D, Sanford B, Schmidt H, Haussler D, Maltbie D (2014) The Cancer Genomics Hub (CGHub): overcoming cancer through the power of torrential data. Database (Oxford) 2014: bau093.

Zhao S, Prenger K, Smith L, Messina T, Fan H, Jaeger E, Stephens S (2013) Rainbow: a tool for large-scale whole-genome sequencing data analysis using cloud computing. BMC Genomics 14: 425-425.

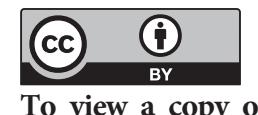

This work is licensed under the Creative Commons Attribution 4.0 International License. To view a copy of this license, visit http://creativecommons.org/ licenses/by/4.0/ 